\title{
Penggunaan Berbagai Amelioran Terhadap Perbaikan Sifat Kimia Tanah Sawah Bukaan Baru dan Hasil Padi Lokal Tipe Baru
}

\author{
(The use of various ameliorants to improve the chemical properties of new open rice fields \\ and new types of local rice)
}

\author{
Rozatul Mastura ${ }^{1}$, Yadi Jufri ${ }^{1}$, Muyassir ${ }^{1 *}$ \\ ${ }^{1}$ Program Studi Ilmu Tanah, Fakultas Pertanian, Universitas Syiah Kuala
}

\begin{abstract}
Abstrak. Sawah bukaan baru mempunyai berbagai masalah diantaranya mengandung $\mathrm{Al}$ dan Fe tinggi dan bisa meracuni tanaman serta kurangnya unsur hara $\mathrm{P}$ dan K. Jumlah Fe yang tinggi pada lahan sawah bukaan baru terkumpul pada daerah perakaran mengakibatkan akar tanaman tidak dapat berkembang dengan baik. Usaha untuk mengatasi hal tersebut dapat dilakukan dengan pemberian amelioran. Amelioran dapat mengikat $\mathrm{Al}$ dan $\mathrm{Fe}$ sehingga $\mathrm{P}$ tersedia bagi tanaman. Penelitian ini bertujuan memperoleh varietas padi lokal tipe baru yang berproduksi tertinggi dan amelioran terbaik pada lahan sawah bukaan baru. Penelitian ini menggunakan Rancangan Acak Kelompok (RAK) Faktorial dengan 9 perlakuan dan 3 kelompok sehingga terdapat 27 satuan unit percobaan. Faktor yang diteliti adalah galur mutan/varietas padi lokal tipe baru dan amelioran. Faktor galur mutan/varietas padi lokal tipe baru dengan terdiri atas: Sanberasi U1, Sanberasi U3 dan Inpari 30 sedangkan faktor amelioran terdiri atas: Kontrol, Arang Sekam dan Kompos Jerami. Untuk melihat perbedaan hasil perlakuan digunakan uji $\mathrm{F}$ dan dilanjutkan dengan uji $\left(\mathrm{BNT}_{0,05}\right)$. Hasil penelitian menunjukkan perlakuan amelioran tidak berpengaruh nyata terhadap N-total, P-tersedia dan K-dd sawah bukaan baru. Varietas padi lokal tipe baru yang berproduksi tertinggi pada lahan sawah bukaan baru yaitu galur Sanberasi U3 dengan amelioran berupa arang sekam dengan hasil rata-rata 13,52 ton $\mathrm{ha}^{-1}$.
\end{abstract}

Kata Kunci: Sawah Bukaan Baru, Padi Lokal Tipe Baru, Amelioran, Sifat Kimia Tanah.

Abstract. New opening rice fields have various problems including high $\mathrm{Al}$ and $\mathrm{Fe}$ content and can poison plants and lack of $\mathrm{P}$ and $\mathrm{K}$ nutrients. The high amount of $\mathrm{Fe}$ in new open field rice fields collected in the root area causes the roots of the plant to not develop properly. Efforts to overcome this can be done by giving amelioran. Amelioran can bind $\mathrm{Al}$ and $\mathrm{Fe}$ so that $\mathrm{P}$ is available for plants. This study aims to obtain the highest yielding new type of local rice varieties and the best ameliorants in new open field rice fields. This study used Factorial Randomized Block Design with 9 treatments and 3 groups so that there were 27 unit test units. The factors studied were new types of mutants / local rice varieties and ameliorants. The new type of mutant / local rice strain factor consists of: Sanberation U1, Sanberation U3 and Inpari 30 while ameliorant factors consist of: Control, Husk Charcoal and Compost Straw. To see the difference in treatment results, the F test was used and continued with the test $\left(\mathrm{BNT}_{0.05}\right)$. The results showed that ameliorant treatment had no significant effect on $\mathrm{N}$ total, P-available and K-dd rice fields of new openings. The new type of local rice varieties that produce the highest in new open rice fields are the U3 Sanberation line with ameliorant in the form of husk charcoal with an average yield of 13.52 tons $\mathrm{ha}^{-1}$.

Keywords: New Opening rice fields, New Type of Local Rice, Amelioran, Soil Chemical Properties

\section{PENDAHULUAN}

Dalam upaya mempertahankan swasembada beras pemerintah telah melaksanakan program ekstensifikasi dengan membuka lahan sawah bukaan baru. Pada program ekstensifikasi daerah pertanian di luar daerah Jawa, pemerintah sudah membuka areal sawah bukaan baru di Sumatera, Kalimantan, dan Sulawesi (Agus et al., 2004). Lahan potensial untuk dijadikan sawah di Provinsi Aceh seluas 68.261 ha, yaitu lahan rawa 3.660 ha dan nonrawa 64.601 ha. Pada tahun 2017 perluasan sawah baru mencapai 15.000 ha dan pada tahun 2018 ditingkatkan lagi 6.000 ha (Ritung dan Suharta, 2007).

Pengembangan lahan sawah bukaan baru diarahkan di daerah luar Jawa. Lahan untuk pengembangan sawah irigasi di luar Jawa yang umumnya adalah tanah Ultisol dan Oxisol (Suharta et al., 1994 dalam Karama, 1998). Menurut Hartatik et al., (2007) tanah itu 
umumnya mengandung $\mathrm{Al}$ dan Fe tinggi yang bisa meracuni tanaman, Kurangnya unsur hara $\mathrm{P}$ dan K. Jumlah Fe yang tinggi pada lahan sawah bukaan baru terkumpul pada daerah perakaran, yang bisa mengakibatkan akar tanaman tidak dapat berkembang. Selain itu tanaman tidak bisa meresap unsur hara dari dalam tanah.

Usaha untuk memperbaiki hal tersebut bisa dilakukan dengan penambahan amelioran pada lahan sawah bukaan baru. Amelioran adalah bahan yang ditambahkan ke dalam tanah agar dapat memperbaiki lingkungan akar tanaman. Amelioran diberikan ke tanah sebagai sumber hara, mengurangi kemasaman tanah dan pengkhelat kation-kation yang mudah tercuci serta meningkatkan kesuburan tanah di lahan pertanian (Adimihardja dan Sutono, 2005 dalam Marham, 2005).

Padi Tipe Baru (PTB) merupakan varietas padi dengan ideotipe yang memberikan keuntungan dalam meningkatkan keseimbangan source dan sink (potensi hasil) (Las et al., 2003). PTB memiliki potensi hasil lebih tinggi dibandingkan varietas unggul baru. Oleh sebab itu, pembentukan PTB perlu dilakukan untuk meningkatan produktivitas dan produksi padi (Abdullah et al., 2008).

Berdasarkan permasalahan pada lahan sawah bukaan baru, maka diperlukan penambahan amelioran berupa bahan organik ke tanah sawah bukaan baru dan informasi jenis varietas padi lokal tipe baru yang unggul pada sawah bukaan baru dalam upaya untuk meningkatkan kualitas tanah dan hasil padi sawah bukaan baru.

\section{METODE PENELITIAN}

Penelitian ini dilaksanakan di lahan sawah bukaan baru milik masyarakat yang dicetak pada tahun 2016 di Desa Teureubeh Kecamatan Kota Jantho Kabupaten Aceh Besar. Analisis sampel tanah, biochar dan kompos jerami dilakukan di Laboratorium Penelitian Tanah dan Tanaman Fakultas Pertanian Universitas Syiah Kuala. Penelitian ini berlangsung dari 16 Desember 2017 - 21 Mei 2018.

\section{MATERI DAN METODE}

Alat yang dipakai dalam penelitian ini yaitu: bor tanah dan plastik berukuran $1 \mathrm{~kg}$ untuk pengambilan sampel tanah, cangkul dan garu untuk peralatan pengolahan tanah, timbangan analitik untuk menimbang pupuk, label perlakuan dimasing-masing plot dan alatalat di Laboratorium.

Bahan yang dipakai dalam penelitian ini yaitu: benih galur mutan Sanberasi U1 dan Sanberasi U3, benih varietas lokal tipe baru Inpari 30, kompos jerami, biochar berupa bahan baku sekam padi, pupuk dasar Urea, SP-36 dan $\mathrm{KCl}$ dan beberapa bahan kimia untuk analisis di Laboratorium.

Penelitian ini memakai Rancangan Acak Kelompok (RAK) Faktorial dengan 9 perlakuan dan terdapat 3 kelompok sehingga terdapat 27 satuan unit percobaan. Faktor yang diteliti adalah galur mutan/varietas padi lokal tipe baru dan amelioran. Faktor 1 adalah galur mutan/varietas padi lokal tipe baru dengan 3 taraf yaitu: $\mathrm{V}_{1}=$ Sanberasi $\mathrm{U} 1, \mathrm{~V}_{2}=$ Sanberasi $\mathrm{U} 3, \mathrm{~V}_{3}=$ Inpari 30. Faktor 2 adalah amelioran dengan 3 taraf yaitu: $\mathrm{A}_{0}=\mathrm{Kontrol}, \mathrm{A}_{1}=$ Arang Sekam, $\mathrm{A}_{2}=$ Kompos Jerami.

Penggunaan Berbagai Amelioran Terhadap Perbaikan Sifat Kimia Tanah Sawah Bukaan Baru dan Hasil Padi Lokal Tipe Baru 


\section{Pelaksanaan Penelitian}

\section{Pengolahan Tanah}

Pengolahan tanah dilakukan satu bulan sebelum percobaan yang meliputi: pembabatan, pembersihan sisa-sisa gulma dan pembajakan tanah sampai tanah siap untuk ditanami varietas padi lokal tipe baru. Sebelum dilakukan penanaman lebih dahulu dibuat plot-plot percobaan. Ukuran plot adalah $1,2 \mathrm{~m} \times 3 \mathrm{~m}$ dan jarak antar kelompok $40 \mathrm{~cm}$. Setiap kelompok dibuat saluran air untuk mengontrol dan mengendalikan pengairan pada plot percobaan.

\section{Persiapan Benih dan Persemaian}

Benih yang telah tersedia diseleksi terlebih dahulu, yaitu dengan cara memilih benih yang bernas. Penyeleksian benih ini bertujuan untuk meminimalkan resiko kegagalan yang terjadi pada penelitian akibat benih yang digunakan tidak tumbuh. Benih sebelum disemai terlebih dahulu dikecambahkan pada media kapas dan dijemur selama 5 menit, kemudian benih yang telah berkecambah disemai selama 10 hari pada media tray yang telah diisi tanah hasil pengayakan.

\section{Penanaman}

Penanaman dilakukan pada saat bibit berumur 12 hari setelah semai (HSS). Penanaman dilakukan dengan cara memindahkan bibit ke lapangan masing- masing 1 tanaman per lubang tanam dengan jarak tanam $25 \times 25 \mathrm{~cm}$. Jumlah tanaman dalam 1 plot adalah 60 tanaman dengan luas plot $1,2 \mathrm{~m}$ x $3 \mathrm{~m}$. Dua minggu sebelum penanaman padi diberikan perlakuan amelioran berupa kompos jerami padi dan arang sekam dengan cara sebar dan diaduk merata dengan tanah. Pemberian kompos dan biochar adalah 20 ton ha ${ }^{-1}$. Adapun pemberian biochar dan kompos jerami per plotnya masing-masing $7,20 \mathrm{~kg} \mathrm{ha}^{-1}$.

\section{Pemupukan}

Pemberian pupuk dasar diberikan dengan dosis Urea $200 \mathrm{~kg} \mathrm{ha}^{-1}$ yaitu pada saat penanaman dan pada saat umur $30 \mathrm{HST}$, SP-36 dan $\mathrm{KCl}$ masing-masing $100 \mathrm{~kg} \mathrm{ha}^{-1}$ diberikan pada saat penanaman. Adapun dosis masing-masing pupuk Urea, SP-36 dan $\mathrm{KCl}$ per plotnya yaitu 36 gram.

\section{Pengairan}

Sawah bukaan baru ini merupakan sawah tadah hujan sehingga sistem pengairannya menggunakan air hujan.

\section{Pemeliharan}

Pemeliharaan yang dilakukan berupa penyiangan yang dilakukan setiap 2 minggu sekali atau tergantung pertumbuhan gulma dilapangan. Penyulaman dilakukan pada saat tanaman 7 HST dengan mencabut tanaman yang mati dan menggantikannya dengan tanaman yang pertumbuhannya lebih sehat. Untuk mengendalian hama dan penyakit memakai insektisida ramah lingkungan.

\section{Panen}

Panen dilakukan pada saat tanaman padi telah menguning pada satu rumpun tanaman dan daun sudah mengering. Gabah juga sudah menguning dan keras, sehingga sukar dipecahkan. Panen dilakukan dengan cara menyabit rumpun tanaman padi kemudian

Penggunaan Berbagai Amelioran Terhadap Perbaikan Sifat Kimia Tanah Sawah Bukaan Baru dan Hasil Padi Lokal Tipe Baru 
gabah dirontokkan. Umur panen galur mutan Sanberasi U3 dan varietas Inpari 30 adalah 100 hari setelah semai dan umur panen galur mutan Sanberasi U1 adalah 110 hari setelah semai.

\section{Parameter Pengamatan}

Parameter sifat kimia yang diamati di laboratorium adalah Nitrogen (\%), Fosfor (\%) dan Kalium (\%). Komponen hasil padi yang diamati yaitu persentase gabah bernas per rumpun $(\%)$, persentase gabah hampa per rumpun (\%), bobot 1000 butir gabah $(\mathrm{g})$, hasil ubinan $(\mathrm{kg})$, dan potensi hasil per hektar (ton).

\section{HASIL DAN PEMBAHASAN}

Hasil analisis tanah sawah bukaan baru yang dilaksanakan pada Desa Teureubeh Kecamatan Kota Jantho Kabupaten Aceh Besar disajikan pada Tabel 1 dan Hasil analisis amelioran disajikan dalam tabel 2.

Tabel 1. Hasil Analisis Tanah Awal

\begin{tabular}{lcc}
\hline Analisis Kimia Tanah & Nilai & Kriteria \\
\hline C-organik $(\%)$ & 0.97 & Sangat rendah \\
N-total $(\%)$ & 0.12 & Rendah \\
P-tersedia $(\mathrm{mg} / \mathrm{kg})$ & 0.30 & Sangat rendah \\
K-dapat ditukar $(\mathrm{cmol} / \mathrm{kg})$ & 0.13 & Sangat rendah \\
$\mathrm{KTK}(\mathrm{cmol} / \mathrm{kg})$ & 10.80 & Rendah \\
$\mathrm{KB}(\%)$ & 35.09 & Rendah \\
$\mathrm{pH} \mathrm{H} \mathrm{H}_{2} \mathrm{O}$ & 5.40 & Masam \\
\hline
\end{tabular}

Tabel 2. Hasil Analisis Amelioran

\begin{tabular}{|c|c|c|}
\hline \multirow{2}{*}{ Aspek } & \multicolumn{2}{|c|}{ Amelioran } \\
\hline & Arang Sekam & Kompos Jerami \\
\hline C-Organik (\%) & 1.16 & 2.92 \\
\hline N-total $(\%)$ & 0.10 & 0.74 \\
\hline P-total (\%) & 0.14 & 0.94 \\
\hline K-total $(\%)$ & 0.04 & 0.92 \\
\hline $\mathrm{pH} \mathrm{H} \mathrm{H}_{2} \mathrm{O}$ & 9.04 & 7.17 \\
\hline $\mathrm{C} / \mathrm{N}(\%)$ & 11,6 & 3,94 \\
\hline
\end{tabular}

Tabel 1 menunjukkan sifat kimia sampel tanah awal memiliki C-organik, P-tersedia dan K-dd yang tergolong sangat rendah, N-total, KTK dan KB tergolong rendah dan $\mathrm{pH}$ $\mathrm{H}_{2} \mathrm{O}$ tergolong masam. Berdasarkan hasil analisis tersebut, tanah sawah bukaan baru ini memiliki tingkat kesuburan yang sangat rendah. Tabel 2 menunjukkan bahwa sifat kimia tanah amelioran menunjukkan kriteria yang masih rendah. 


\section{Analisis Sifat Kimia Tanah}

\section{N-total, P-tersedia dan K-dd}

Hasil analisis ragam menunjukkan bahwa perlakuan amelioran secara tunggal maupun interaksi berpengaruh tidak nyata terhadap N-total, P-tersedia dan K-dd tanah. Rata-rata N-total, P-tersedia dan K-dd tanah akibat pengaruh varietas dan amelioran disajikan pada Tabel 3.

Tabel 3. Rata-rata N-total P-tersedia dan K-dd Tanah Akibat Perlakuan Varietas dan Amelioran

\begin{tabular}{lccc}
\hline \multirow{2}{*}{ Perlakuan } & \multicolumn{3}{c}{ N-total $(\%)$} \\
\cline { 2 - 4 } & Kontrol & Arang Sekam & Kompos Jerami \\
\hline Sanberasi U1 & 0,11 & 0,14 & 0,10 \\
Sanberasi U3 & 0,12 & 0,18 & 0,13 \\
Inpari 30 & 0,11 & 0,11 & 0,09 \\
\hline & \multicolumn{3}{|c}{0,57} \\
Sanberasi U1 & 1,90 & P-tersedia $(\mathrm{mg} / \mathrm{kg})$ \\
Sanberasi U3 & 1,23 & 1,50 \\
Inpari 30 & 1,78 & 1,17 & 0,32 \\
\hline & & 1,33 & 0,30 \\
Sanberasi U1 & 0,22 & K-dd $(\mathrm{cmol} / \mathrm{kg})$ & 0,34 \\
Sanberasi U3 & 0,22 & 0,16 & 0,18 \\
Inpari 30 & 0,27 & 0,25 & 0,24 \\
\hline
\end{tabular}

Perlakuan amelioran tidak memberikan pengaruh yang nyata terhadap sifat kimia tanah N-total, P-tersedia dan K-dd tanah. Hal ini diduga karna suplai hara N, P dan K yang bersumber dari amelioran yang diberikan masih rendah (Tabel 2). Nurhayati (2010) dalam Surtinah (2013) menyatakan kompos yang baik mengandung unsur hara $\mathrm{N}$-total $>1.5 \%$, P-total > 1\%, dan K-total > $1.5 \%$, rasio $\mathrm{C} / \mathrm{N}$ antara $15-20$. Jika rasio $\mathrm{C} / \mathrm{N}$ terlalu rendah, Nitrogen yang tidak digunakan oleh mikroba tidak bisa diasimilasi sehingga hilang melalui volatisasi sebagai $\mathrm{NH}_{3}$ atau terdenitrifikasi (Djuarnani et al., 2005). Selain itu berdasarkan hasil analisis tanah awal diketahui kesuburan tanahnya sangat rendah (Tabel 1). Dengan demikian kandungan hara N-total, P-tersedia dan K-dd yang ditambahkan pada lahan sawah bukaan baru belum dapat meningkatkan suplai hara sesuai kebutuhan tanaman padi.

Perlakuan amelioran tidak memberikan pengaruh yang nyata terhadap sifat kimia tanah N-total, P-tersedia dan K-dd tanah juga diduga karena pengambilan sampel tanah yang dilakukan pada saat panen sehingga sebagian unsur hara yang terdapat di dalam tanah telah digunakan tanaman untuk kebutuhan hidupnya. Hal ini sesuai dengan penelitian Sunardi dan Sarjono (2007) yang menyatakan bahwa sedikitnya kadar nitrogen pada waktu pemanenan dalam tanah disebabkan jumlah nitrogen digunakan oleh tanaman cukup banyak. Di samping itu N-organik sangat larut dan mudah menghilang pada saat pencucian. Tanaman menyerap hara $\mathrm{N}$ dalam bentuk Nitrat $\left(\mathrm{NO}_{3}^{-}\right)$dan Amonium $\left(\mathrm{NH}_{4}{ }^{+}\right)$

Penggunaan Berbagai Amelioran Terhadap Perbaikan Sifat Kimia Tanah Sawah Bukaan Baru dan Hasil Padi Lokal Tipe Baru 
dan $\mathrm{P}$ dalam bentuk ion ortofosfat $\left(\mathrm{H}_{2} \mathrm{PO}_{4}{ }^{-}\right)$dan ion ortofosfat sekunder $\left(\mathrm{HPO}_{4}{ }^{2-}\right)$ serta kalium dalam bentuk ion $\mathrm{K}^{+}$.

\section{Potensi Hasil Padi Lokal Tipe Baru}

\section{Persentase Gabah Bernas dan Hampa}

Hasil analisis ragam menunjukkan bahwa perlakuan varietas dan amelioran secara tunggal maupun interaksi berpengaruh tidak nyata terhadap presentase gabah bernas dan gabah hampa padi lokal tipe baru. Rata-rata presentase gabah bernas dan gabah hampa akibat pengaruh varietas dan amelioran disajikan pada Tabel 4.

Tabel 4. Rata-rata Persentase Gabah Bernas dan Gabah Hampa Akibat Perlakuan Varietas dan Amelioran

\begin{tabular}{lcccccc}
\hline \multirow{2}{*}{ Perlakuan } & \multicolumn{3}{c}{ Gabah Bernas (\%) } & \multicolumn{3}{c}{ Gabah Hampa (\%) } \\
\cline { 2 - 7 } & Kontrol & $\begin{array}{c}\text { Arang } \\
\text { Sekam }\end{array}$ & $\begin{array}{c}\text { Kompos } \\
\text { Jerami }\end{array}$ & Kontrol & $\begin{array}{c}\text { Arang } \\
\text { Sekam }\end{array}$ & $\begin{array}{c}\text { Kompos } \\
\text { Jerami }\end{array}$ \\
\hline Sanberasi U1 & 86,68 & 88,14 & 87,97 & 13,32 & 11,86 & 12,03 \\
Sanberasi U3 & 87,07 & 89,27 & 88,04 & 12,93 & 10,73 & 11,96 \\
Inpari 30 & 81,05 & 90,54 & 90,17 & 19,25 & 9,46 & 9,83 \\
\hline
\end{tabular}

Presentase gabah bernas tidak menunjukkan hasil yang berbeda nyata karena sumber hara yang diperoleh berasal dari pupuk dasar SP-36 yang menyediakan unsur hara fosfor bagi tanaman dan diberikan dengan dosis yang sama pada sawah bukaan baru. Sutedjo (2002) menyatakan fosfor bermanfaat mempercepat pembungaan sehingga juga mempercepat pemasakan buah dan biji dan dapat menaikkan hasil biji-bijian. Amelioran yang diberikan berfungsi sebagai pengkhelat $\mathrm{Al}$ dan Fe pada tanah sawah bukaan baru. Amelioran berupa bahan organik mengandung unsur hara dengan jumlah yang sedikit. Ginting (2010) menyatakan bahan organik memiliki unsur hara makro (unsur hara yang banyak dibutuhkan tanaman) dan mikro (unsur hara yang sedikit dibutuhkan tanaman) yang lengkap, tetapi dalam jumlah sedikit.

Meskipun faktor genetik dari setiap tanaman padi lokal tipe baru berbeda namun perlakuan amelioran belum mampu memberikan keragaman terhadap presentase bernas dan hampa padi lokal tipe baru yang ditanam pada sawah bukaan baru. Mahmud dan Sulistyo (2014) dalam Mawardi et al., (2016) mengatakan persentase gabah bernas yang tinggi per malai sangat dipengaruhi oleh jumlah gabah per malai dan kecukupan hara yang tersedia. Situasi lingkungan tumbuh yang sesuai condong merangsang proses inisiasi malai menjadi sempurna, sehingga peluang keluarnya bakal gabah menjadi lebih banyak. Tapi makin banyak gabah yang terbentuk dapat menaikkan beban tanaman pada saat pembentukan gabah isi. Jikalau pada saat proses gabah terisi, tidak diimbangi dengan hara yang tersedia secara cukup maka berakibat banyaknya gabah hampa. Persentase gabah bernas adalah salah satu indikator produktivitas tanaman, semakin tinggi persentase gabah isi suatu varietas menandakan bahwa varietas tersebut memiliki hasil yang tinggi.

\section{Bobot 1000 butir}

Hasil analisis ragam menunjukkan bahwa perlakuan varietas secara tunggal berpengaruh nyata terhadap bobot 1000 butir padi. Rata-rata bobot 1000 butir akibat pengaruh varietas dan amelioran disajikan pada Tabel 5 . 
Tabel 5. Rata-rata Bobot 1000 butir Akibat Perlakuan Varietas dan Amelioran

\begin{tabular}{lccc}
\hline \multirow{2}{*}{ Perlakuan } & \multicolumn{3}{c}{ Bobot 1000 butir $(\mathrm{g})$} \\
\cline { 2 - 4 } & Kontrol & Arang Sekam & Kompos Jerami \\
\hline Sanberasi U1 & $35,50 \mathrm{a}$ & $34,29 \mathrm{a}$ & $37,25 \mathrm{a}$ \\
Sanberasi U3 & $45,95 \mathrm{~b}$ & $45,37 \mathrm{~b}$ & $46,08 \mathrm{~b}$ \\
Inpari 30 & $47,56 \mathrm{~b}$ & $47,90 \mathrm{~b}$ & $48,88 \mathrm{~b}$ \\
\hline
\end{tabular}

$\mathrm{BNT}_{0,05}$

3,45

Keterangan: angka yang diikuti oleh huruf yang sama pada kolom yang sama tidak berbeda nyata pada $\mathrm{BNT}_{0,05}$.

Pada Tabel 5 terlihat bahwa rata-rata bobot 1000 butir varietas padi tertinggi terdapat pada Varietas Inpari 30 yang tidak berbeda nyata dengan Galur Sanberasi U3 tapi berbeda nyata dengan Galur Sanberasi U1. Perlakuan varietas menunjukkan hasil yang berbeda nyata diduga karena perbedaan genetik varietas. Hal ini sesuai dengan pernyataan Yoshida (1981) bahwa bobot 1000 butir gabah bernas lebih ditentukan oleh sifat genetiknya.

Perlakuan amelioran tidak menunjukkan pengaruh yang nyata terhadap bobot 1000 butir tanah. Hasil penelitian ini sesuai dengan penelitian Rahayu dan Harjoso (2010) yang menyatakan bahwa abu sekam yang diberikan tidak menunjukkan pengaruh yang nyata terhadap bobot 1000 butir gabah sedangkan perbedaan varietas yang dicoba menunjukkan perbedaan terhadap bobot 1000 butir. Varietas Aek Sibundong memiliki nilai tertinggi, dibandingkan dengan varietas Towuti, Situ Patenggang, Limboto, dan varietas Batutegi memiliki nilai terendah.

\section{Hasil Ubinan dan Potensi Hasil per Hektar}

Hasil analisis ragam menunjukkan bahwa perlakuan varietas dan amelioran secara tunggal maupun interaksi berpengaruh nyata terhadap hasil per ubinan dan potensi hasil per hektar. Rata-rata hasil Ubinan dan potensi hasil per Hektar akibat pengaruh varietas dan amelioran disajikan pada Tabel 6.

Tabel 6. Rata-rata Hasil Ubinan dan Potensi Hasil per Hektar Akibat Perlakuan Varietas dan Amelioran

\begin{tabular}{lcccccc}
\hline \multirow{2}{*}{ Perlakuan } & \multicolumn{3}{c}{ Hasil Ubinan $(\mathrm{kg})$} & \multicolumn{2}{c}{ Potensi Hasil per Hektar (ton) } \\
\cline { 2 - 7 } & Kontrol & $\begin{array}{c}\text { Arang } \\
\text { Sekam }\end{array}$ & $\begin{array}{c}\text { Kompos } \\
\text { Jerami }\end{array}$ & Kontrol & $\begin{array}{c}\text { Arang } \\
\text { Sekam }\end{array}$ & $\begin{array}{c}\text { Kompos } \\
\text { Jerami }\end{array}$ \\
\hline \multirow{2}{*}{ Sanberasi U1 } & $1,27 \mathrm{a}$ & $1,44 \mathrm{a}$ & $1,34 \mathrm{a}$ & $7,26 \mathrm{a}$ & $8,21 \mathrm{a}$ & $7,67 \mathrm{a}$ \\
& $\mathrm{A}$ & $\mathrm{A}$ & $\mathrm{A}$ & $\mathrm{A}$ & $\mathrm{A}$ & $\mathrm{A}$ \\
Sanberasi U3 & $1,59 \mathrm{a}$ & $2,37 \mathrm{~b}$ & $1,63 \mathrm{a}$ & $9,08 \mathrm{a}$ & $13,52 \mathrm{~b}$ & $9,31 \mathrm{a}$ \\
& $\mathrm{B}$ & $\mathrm{B}$ & $\mathrm{AB}$ & $\mathrm{B}$ & $\mathrm{B}$ & $\mathrm{B}$ \\
Inpari 30 & $1,68 \mathrm{a}$ & $2,29 \mathrm{~b}$ & $1,73 \mathrm{a}$ & $9,58 \mathrm{a}$ & $13,09 \mathrm{~b}$ & $9,88 \mathrm{a}$ \\
& $\mathrm{B}$ & $\mathrm{B}$ & $\mathrm{B}$ & $\mathrm{B}$ & $\mathrm{B}$ & $\mathrm{B}$ \\
\hline \multirow{2}{*}{ BNT $_{0,05}$} & & 0,30 & & & 1,59 & \\
\hline
\end{tabular}

Keterangan: angka yang diikuti oleh huruf yang sama pada kolom yang sama tidak berbeda nyata pada $\mathrm{BNT}_{0,05}$. Huruf kapital dibaca secara vertikal dan huruf kecil dibaca secara horizontal.

Penggunaan Berbagai Amelioran Terhadap Perbaikan Sifat Kimia Tanah Sawah Bukaan Baru dan Hasil Padi Lokal Tipe Baru 
Pada Tabel 6 terlihat bahwa rata-rata hasil per ubinan dan hasil per hektar tertinggi terdapat pada galur Sanberasi U3 dengan amelioran arang sekam yang tidak berbeda nyata dengan varietas Inpari 30 dengan amelioran arang sekam tapi berbeda nyata dengan semua kombinasi perlakuan lainnya. Perbedaan genetik pada masing-masing varietas menjadi salah satu yang dapat menyebabkan perbedaan hasil atau produksi. Hal ini sesuai dengan pernyataan Kamal (2001) dalam Lestari (2012), perbedaan produksi total disebabkan oleh perbedaan komposisi genetik pada masing-masing kultivar padi, sehingga responnya terhadap lingkungan juga berbeda.

Pemberian amelioran dapat meningkatkan hasil padi. Jalid dan Hirwan (1987); Burbey dan Yusril (1989) dalam Agus (2004) dalam penelitiannya menjelaskan pemberian amelioran di sawah bukaan baru yang diberikan kapur dan pupuk kandang bisa menaikkan hasil padi dan memberikan penurunan keracunan besi. Kapur sebanyak 1 ton yang diberikan dan pupuk kandang sebanyak 5 ton $\mathrm{ha}^{-1}$ dan pemberian pupuk NPK dapat menaikkan hasil padi 1- 2 ton dibandingkan dengan kontrol.

\section{KESIMPULAN DAN SARAN}

Pemberian amelioran belum dapat memperbaiki sifat kimia N-total, P-tersedia dan K-dd tanah sawah bukaan baru dan galur mutan padi lokal tipe baru Sanberasi U3 dengan amelioran arang sekam sebanyak 20 ton/ha menghasilkan padi tertinggi yaitu sebesar 13,52 ton $\mathrm{ha}^{-1}$.

\section{DAFTAR PUSTAKA}

Abdullah, B. S. Tjokrowidjojo dan Sularjo. 2008. Perkembangan dan prospek perakitan padi tipe baru di Indonesia. Litbang Pertanian. 27(1): 1-9.

Agus, F., A. Adimihardja., S. Hardjowigeno., A.M. Fagi dan W. Hartatik. 2004. Tanah Sawah dan Teknologi Pengelolaannya. Pusat Penelitian dan Pengembangan Tanah dan Agroklimat (Puslitbangtanak), Jawa Barat.

Djuarnani, N., Kristian dan B.S. Setiawan. 2005. Cara Cepat Membuat Kompos. Agromedia, Jakarta.

Ginting. 2010. Akumulasi Logam Berat di Perairan. Rineka Cipta, Jakarta.

Hartatik, W., Sulaeman dan A. Kasno. 2007. Perubahan Sifat Kimia danAmeliorasi Sawah Bukaan Baru, Lahan Sawah Bukaan Baru. Balai Besar Penelitian dan Pengembangan Sumberdaya Lahan Pertanian, Bogor.

Karama, A.S. (Eds.). 1998. Risalah Hasil Penelitian Sumber daya Lahan untuk Pengembangan Sawah Irigasi di Sumatera. Puslittanak, Bogor.

Las, I., B. Abdullah, dan A.A. Daradjat. 2003. Padi Tipe Baru dan Padi Hibrida Mendukung Ketahanan Pangan. Tabloid Sinar Tani. 30 Juli 2013.

Lestari, A. 2012. Uji daya hasil Beberapa varietas Padi (Oryza sativa L.) dengan metode SRI (The System of Rice Intensification) di Kota Solok. Budidaya Tanaman Pangan. 1-14.

Marham. 2005. Teknologi Pengelolaan Lahan Kering Menuju Petanian Produktif dan Ramah Lingkungan. Pusat Penelitian dan Pengembangan Tanah dan Agroklimat, Bogor. 
Mawardi, C. N. Ichsan dan Syamsuddin. 2016. Pertumbuhan dan hasil beberapa varietas tanaman Padi (Oryza sativa L.) pada tingkat kondisi kekeringan. Ilmiah Mahasiswa Pertanian Unsyiah. 1(1): 176-187.

Novizan. 2001. Petunjuk Pemupukan yang Efektif. Agromedia Pustaka, Tangerang.

Rahayu, A.Y dan T. Harjoso. 2010. Aplikasi abu sekam pada kondisi dibawah kapasitas lapang pada lima Varietas Padi Gogo: hasil dan komponen hasil. Fakultas Pertanian Universitas Jenderal Soedirman. 3(2): 118-125. ISSN 1979 - 5777.

Ritung, S dan N. Suharta, 2007. Sebaran dan Potensi Pengembangan Lahan Sawah Bukaan Baru. Tanah sawah bukaan baru. Balai Besar Penelitian dan Pengembangan Sumberdaya Lahan Pertanian, Bogor.

Sunardi dan Y. Sarjono. 2007. Penentuan kandungan unsur makro pada lahan pasir pantai Samas Bantul dengan metode Analisis Aktiv ASI Neutron (AAN). Pusat Teknologi Akselerator dan Proses Bahan BATAN, Yogyakarta. ISSN 0216-3128.

Surtinah. 2013. Pengujian kandungan unsur hara dalam kompos yang berasal dari serasah tanaman jagung manis (Zea mays saccharata). Ilmiah Pertanian. Program Studi Agroteknologi, Fakultas Pertanian, Universitas Lancang Kuning. 11(1): 16-25.

Sutedjo, M. M. 2002. Pupuk dan Cara Pemupukan. Rineka Cipta, Jakarta.

Yoshida, S. 1981. Fundamentals of Rice Crop Science International Rice Research Institute. Los Banos, laguna, Philippines. 